\title{
GÊNERO, CIÊNCIA, TECNOLOGIA E DESENVOLVIMENTO: AS CONCEPÇÕES DESSAS CATEGORIAS NOS DOCUMENTOS FUNDANTES DO PROEJA
}

\section{Gender, Science, Technology and Development: The Conceptions of These Categories in the Founding Documents PROEJA}

Nadia Terezinha Covolan²

Maria Lúcia Buher Machado ${ }^{3}$

\section{Resumo}

Neste trabalho, discutimos as categorias Ciência, Tecnologia e Gênero conforme constam nos documentos fundantes do PROEJA (Programa Nacional de Integração da Educação Profissional com a Educação Básica na Modalidade de Educação de Jovens e Adultos), promulgado pelo Ministério de Educação e Cultura e implantado em vários Institutos de Educação Técnica e Tecnológica do Brasil, a partir de 2007. Este programa tem como objetivo, além da formação profissional, a educação plena para o exercício da vida cidadã, de

2 Pós Doutoranda pelo Programa de Pós-Graduação em Tecnologia (PPGTE) da UTFPR; Doutora em Ciências Humanas pelo DICH/UFSC (2005), Mestre em Tecnologia pelo PPGTE / CEFET-PR (2001); graduada em Filosofia pela UFPR (1989), e em Enfermagem pela UFSC (1979). Especialista em Pensamento Contemporâneo, em Saúde Pública e em Saúde do Trabalho. Docente da UFPR setor litoral, atua no núcleo estruturante do curso de Saúde Coletiva. Membro fundadora do Núcleo de Estudos e Pesquisas em Gênero e Tecnologia (GETEC) do PPGTe / UTFPR desde 2000 e do Grupo de Estudos e Pesquisas em Território, Diversidade e Saúde (TeDiS) da UFPR desde 2014. Pesquisa indicadores de desenvolvimento humano relacionados aos estudos de ciência, tecnologia e sociedade (CTS) considerando a questão de gênero em suas variadas expressões. E-mail: nadiathe@gmail.com

3 Doutora em Educação (2010) pela Universidade Estadual de Campinas (UNICAMP), Mestre em Tecnologia e Trabalho pela Universidade Tecnológica Federal do Paraná (2003), especialista em ensino de História (UFPR) e Bacharel e licenciada em História pela Universidade Federal do Paraná. Desde 2010 é docente com dedicação exclusiva ao Instituto Federal de Educação Ciência e Tecnologia do Paraná, Câmpus Paranaguá. Exerce desde 2012 a coordenação Institucional do Programa Institucional de Bolsas de Iniciação à Docência (PIBID), programa da CAPES voltado para as licenciaturas. E-mail: lucia. buher@ifpr.edu.br 
minorias sociológicas. Nesse contexto, argumentamos sobre as possibilidades e limites do PROEJA especialmente para as mulheres, porque estas somam as desigualdades de oportunidades para formação escolar e profissional com as assimetrias de poder nas relações de gênero, o que compromete o acesso mais equitativo a técnicas e tecnologias libertárias e aos bens socialmente construídos. Por fim, refletimos sobre a vinculação das categorias com vistas ao desenvolvimento pessoal e o das comunidades envolvidas.

Palavras-chaves: PROEJA, Ciência, Tecnologia, Gênero, Desenvolvimento.

\section{Abstract}

In this paper, we discuss the categories Science, Technology and Gender as set out in the founding documents PROEJA (National Program for the Integration of Vocational Education in Basic Education in the Mode of Education Youth and Adults), promulgated by the Ministry of Education and Culture and deployed in various institutes of Technical Education and Technology of Brazil, from 2007. This program aims, in addition to vocational training, education for the full exercise of citizen life, sociological minority. In this context, we argue about the possibilities and limits of PROEJA especially for women, because they add up the inequalities of opportunities for education and vocational training with the asymmetries of power in gender relations, which compromises more equitable access to techniques and technologies libertarian goods and socially constructed. Finally, we reflect on the linking of categories with a view to developing staff and the community involved.

Keywords: PROEJA, Science, Technology, Gender, Development

\section{Introdução}

Neste artigo, discutimos as articulações entre ciência, tecnologia e gênero na política pública do PROEJA - Programa Nacional de Integração da Educação Profissional com a Educação Básica na Modalidade de Educação de Jovens e Adultos -a partir da análise do seu documento fundante, publicado pelo MEC - Ministério da Educação - em 2007 (BRASIL, MEC. 2007). Argumentamos sobre as possibilidades e limites do PROEJA, especialmente para as mulheres, porque estas somam as desigualdades de oportunidades para formação escolar e profissional com as assimetrias de poder nas relações de gênero, o que compromete o acesso mais equitativo a técnicas 
e tecnologias libertárias, o que influencia diretamente o seu desenvolvimento pessoal e por consequência, os das suas comunidades.

Consideramos desenvolvimento conforme os aportes de Amartya Sen em seu livro Desenvolvimento como Liberdade (2000). O autor relaciona desenvolvimento com a expansão das capacidades humanas, para que as pessoas possam ter possibilidades reais de ser e fazer o que consideram importante nas suas vidas. O autor analisa o desenvolvimento humano nos aspectos avaliativo e de agência. O enfoque de desenvolvimento humano é geralmente associado com o aspecto avaliativo que diz respeito a melhoria da vida das pessoas, e menos, com a agência pessoal e coletiva, especialmente no que tange as mulheres. Para o autor, no entanto, a agência feminina influencia diretamente não só seu próprio bem estar, porém, é o cerne do desenvolvimento humano enquanto tal. Assim, qualquer tentativa de aumentar o bem estar feminino não pode deixar de recorrer à condição de agente das mulheres, pois estas são as responsáveis pelas mudanças mais radicais e pelas "transformações sociais que podem alterar a vida das mulheres e dos homens". (SEN, 2012, p. 246)

Nosso interesse pelo tema advém do desenvolvimento de projeto mais amplo, financiado pelo CNPq e intitulado "Igualdade de oportunidades? Análise dos cursos de PROEJA no IFPR/Campus Paranaguá: inserções, permanências, limites e possibilidades de empoderamento de alunos e alunas na perspectiva de gênero, classe social, raça/etnia e geração". Nosso objetivo, enquanto profissionais da educação envolvidas com o PROEJA, é contribuir para o debate e a concretização dessa necessária política educacional, que tem por objetivo contemplar grupos historicamente alijados da educação formal e por conseqüência, dos bens socialmente produzidos.

Por questões didáticas, dividimos o texto em três partes. Na primeira, contextualizamos o PROEJA enquanto política pública educacional com vistas à emancipação de minorias sociológicas. Na segunda, discutirmos a imbricação gênero, ciência e tecnologia, conforme o documento citado. Nas considerações, apresentamos sugestões e questionamentos sobre a vinculação dessas categorias com vistas ao desenvolvimento pessoal das comunidades envolvidas em nosso local de pesquisa, o litoral do Paraná. 


\section{O PROEJA: Contexto e desenvolvimento da política educacional}

Os embates que envolvem os projetos de formação profissional no Brasil, implantados a partir do Estado, expressam em cada contexto os projetos societários estabelecidos para o país. Ao tomarmos como base as discussões engendradas a partir da instauração da República, estendidas ao longo do século $X X$, constatamos como as questões de formação profissional surgem atreladas ao ideal de modernização consideradas imprescindíveis para o desenvolvimento do país, na perspectiva capitalista. (IANNI, 2001; MACHADO, 1998, CIAVATTA FRANCO, 1990). Todavia, se esse foi um ponto de convergência ao longo do século $X X$, não podemos afirmar que houve uma homogeneização nas propostas de formação profissional. Aspectos como a dualidade estrutural (KUENZER, 2007) criticando as distintas trajetórias propostas para o sistema educacional brasileiro - de um lado uma formação profissional para os/as trabalhadores/as, de outro a formação geral para a elite dirigente -, ou ainda o desmantelamento do sistema federal de ensino técnico pela política educacional de Fernando Henrique Cardoso, nos anos de 1990 (LEITE FILHO, 2003) e a posterior retomada do projeto de formação técnico-profissional vinculado à escolarização, implantada pelo governo Lula no início do século XXI evidenciam o campo de disputas que o tema suscita.

O PROEJA foi implantado pelo Governo Federal a partir do Decreto $5478 / 2005$, voltado inicialmente para o oferecimento de educação técnica profissional de nível médio, estabelecendo como base para o seu desenvolvimento a Rede Federal de Educação Profissional e Tecnológica. Em 2006 o Decreto $n^{\circ} 5.840$, de 13 de julho de 2006 é promulgado, alterando alguns encaminhamentos iniciais presentes no decreto anterior, como a ampliação da abrangência, no que concerne ao nível de ensino,incluindo o ensino fundamental, e autorizando que instituições dos sistemas de ensino estaduais e municipais e entidades privadas nacionais de serviço social, aprendizagem e formação profissional, pudessem oferecer o PROEJA, passando a denominação para Programa Nacional de Integração da Educação Profissional com a Educação Básica na Modalidade de Educação de Jovens e Adultos. (BRASIL, 2007, p. 12 ) 
O documento base do PROEJA, referenciado acima, foi expedido em 2007 pela Secretaria de Educação Profissional e Tecnológica, elaborado a partir dessas reformulações. Ao longo do texto apresentado, se faz presente a preocupação em contemplar nessa política, minorias sociológicas amplamente excluídas do sistema educacional formal. Exemplo disso esta na citação abaixo, que ressalta parte do percurso vivenciado por alunos e alunas que buscam o Programa:

\begin{abstract}
Assim, mais tarde esses jovens retornam, via EJA, convictos da falta que faz a escolaridade em suas vidas, acreditando que a negativa em postos de trabalho e lugares de emprego se associa exclusivamente à baixa escolaridade, desobrigando o sistema capitalista da responsabilidade que the cabe pelo desemprego estrutural. A EJA, em síntese, trabalha com sujeitos marginais ao sistema, com atributos sempre acentuados em conseqüência de alguns fatores adicionais como raça/etnia, cor, gênero, entre outros. Negros, quilombolas, mulheres, indígenas, camponeses, ribeirinhos, pescadores, jovens, idosos, subempregados, desempregados, trabalhadores informais são emblemáticos representantes das múltiplas apartações que a sociedade brasileira, excludente, promove para grande parte da população desfavorecida econômica, social e culturalmente.(BRASIL, 2006, p. 11)
\end{abstract}

O documento apresenta seis princípios que fundamentam a política do PROEJA e que podem ser assim resumidos e destacados: 1) O papel e compromisso das entidades públicas integrantes dos sistemas educacionais com a inclusão da população em suas ofertas educacionais; a inclusão aqui compreendida como acesso do direito à escola, a permanência e o sucesso dos alunos nas unidades escolares. 2). A inserção orgânica da modalidade EJA integrada à educação profissional nos sistemas educacionais públicos. A perspectiva da educação como direito -assegurada pela Constituição no nível de ensino fundamental como dever do Estado; 3) a universalização do ensino médio , compreendendo que a formação exige períodos longos, para consolidar saberes, e transformar o mundo; 4) compreensão do trabalho como princípio educativo, no sentido do entendimento de que homens e mulheres produzem sua condição humana pelo trabalho - ação transformadora no mundo, de si, para si e para outrem; 5) definição da pesquisa como fundamento da formação para produzir conhecimentos e contribuir para a construção da autonomia intelectual; 6) O sexto princípio 
considera as condições geracionais, de gênero, de relações étnico-raciais como fundantes da formação humana e dos modos como se produzem as identidades sociais, aspecto que passamos a analisar a seguir.

\section{O gênero no documento base do PROEJA: o desafio da visibilidade}

O documento base refere-se às condições geracionais, de gênero e étnico-raciais, como sendo fundantes da formação humana e dos modos como se produzem as identidades sociais. Assim, outras categorias para além da de "trabalhadores", são consideradas por serem constituintes das identidades e não se dissociarem dos modos de ser e estar no mundo de jovens e adultos. (BRASIL, 2007, p.38). No documento, em vários momentos, aponta-se a somatória de fatores que acentuam as discriminações. Como todo texto escrito coletivamente, se desvela aqui e ali, o olhar de quem colaborou na sua escrita. Nesse contexto, aparecem os frutos dos esforços empreendidos pelos movimentos feministas, de mulheres, de profissionais homens e mulheres que estudam gênero, para trabalhar esta categoria tendo em vista as minorias sociológicas em geral e a feminina em particular. Chama atenção a forma como a categoria gênero esta posta ao longo desse documento tão importante, desde os usos da linguagem até os lugares de fala, como no exemplo abaixo, quando trata da educação para grupos excluídos:

A grave situação educacional que os números revelam exige refletir quanto têm estado equivocadas as políticas públicas para a educação de jovens e adultos, restritas, no mais das vezes, à questão do analfabetismo, sem articulação com a educação básica como um todo, nem com a formação para o trabalho, nem com as especificidades setoriais, traduzidas pelas questões de gênero, raça, espaciais (campo - cidade), geracionais etc.(BRASIL, 2007, p. 20) 
Apesar da forte menção à categoria, não há uma definição propriamente dita de gênero. Esse "descuido" demonstra na realidade as muitas mãos que escreveram esse texto e como o gênero segue sendo a luta de poucas e poucos. A lacuna é apontada, porém, não é preenchida. O feminino, no caso, permanece subsumido ao masculino:

\begin{abstract}
O imenso contingente de jovens que demanda a educação de jovens e adultos, resultante de taxas de abandono de $12 \%$ no ensino fundamental regular e de $16,7 \%$ no ensino médio, acrescido de distorção idade-série de $39,1 \%$ no ensino fundamental e de 53,3\% no ensino médio (BRASIL, 2001), revela a urgência de tratamento não fragmentado, mas totalizante e sistêmico, sem o que se corre o risco de manter invisibilizada socialmente essa população, frente ao sistema escolar e, seguramente, no mundo do trabalho formal, exigente de certificações e comprovações de escolaridade formal. (BRASIL, 2007, p.18)
\end{abstract}

As referências a gênero no documento, em parágrafos especiais e ou subsumidas na linguagem no masculino, faz com que a categoria perca o vínculo com o tecido total do texto. A linguagem no masculino, em todas as instâncias, educacionais, de pesquisas, cientifica e tecnológicas, dificulta lograr a real visibilidade e a efetiva problematização do gênero enquanto categoria de análise histórica e social, que se refere às relações de poder estabelecidas entre homens e mulheres, homens e homens, mulheres e mulheres, adultos e jovens na diversidade social. Nesse sentido, reiteramos com Margaret Lopes (2002), que apesar de todas as discussões sobre ciência, tecnologia e gênero das ultimas décadas e de estarmos sempre trazendo essa discussão em encontros como este, apesar da visibilidade que ganharam esses estudos, ainda estamos longe da inclusão feminina.

Argumentos históricos que tratam das relações de gênero, sobejamente discutidos, explicam o porquê da menor presença feminina em áreas tradicionalmente ocupadas por homens, especialmente nos setores das engenharias e na pesquisa tecnológica aplicada. Várias autoras referem que os órgãos oficiais que coordenam o sistema de C\&T no Brasil não se preocupam com a participação feminina na produção do conhecimento e que somente o olhar de pesquisadoras/es envolvidas/os encontram as mulheres. Assim, refletir sobre ciência, tecnologia e gênero com vistas ao desenvolvimento, permanece sendo um desafio. 


\title{
Ciência, tecnologia e gênero: uma história recente.
}

A expansão da comunidade científica na história do Brasil é recente. No final de 1960, com a edição do Plano Estratégico de Desenvolvimento Nacional, a questão científica e tecnológica surge no planejamento nacional. Assim, a institucionalização da ciência brasileira é um fato tão recente quanto o reconhecimento da questão feminina nela implicada.

O documento PROEJA aborda o modelo de desenvolvimento socioeconômico brasileiro como produto da dependência econômica externa, historicamente baseada nas exportações de matérias-primas, assim como na importação acrítica das tecnologias produzidas nos países de capitalismo avançado. Assim, nosso país ainda se encontra submetido aos indicadores econômicos de fora e as especulações de organismos internacionais de financiamento. (BRASIL, 2007, p. 23). O mesmo documento, no entanto, aponta variadas ações em andamento para a consolidação de um projeto educacional que integre trabalho, ciência, técnica, tecnologia, com vistas ao enriquecimento científico, cultural, político e profissional e como condições necessárias para o efetivo exercício da cidadania:

\begin{abstract}
Por esse entendimento, não se pode subsumir a cidadania à inclusão no "mercado de trabalho", mas assumir a formação do cidadão que produz, pelo trabalho, a si e o mundo. Esse largo mundo do trabalho - não apenas das modernas tecnologias, mas de toda a construção histórica que homens e mulheres realizaram, das mais simples, cotidianas, inseridas e oriundas no/do espaço local até as mais complexas, expressas pela revolução da ciência e da tecnologia - força o mundo contemporâneo a rever a própria noção de trabalho (e de desenvolvimento) como inexoravelmente ligada à revolução industrial. (BRASIL, 2007, p. 13)
\end{abstract}

Sabemos que, de muitas formas, a Ciência e as tecnologias constituem cada vez mais a cultura contemporânea e embasam a economia e o desenvolvimento das regiões e do país. No entanto, pelo olhar herdado da modernidade, a Ciência é concebida como a exclusiva produtora de riquezas e bem-estar social e a tecnologia é tida como autônoma; nesse viés, 
o cientista pesquisador - representado geralmente no masculino - é visto como a pessoa que, na busca da "verdade cientifica", está livre de valores não cognitivos. Ora, quem faz ciência e tecnologia é o ser humano que valora, e esses valores influenciam diretamente o que se quer conhecer, como se conhece e o próprio conhecimento. Os saberes científicos e tecnológicos estão impregnados pelos interesses militares, políticos, de gênero, étnicos dentre outros. Até recentemente, lembramos, a ciência, por exemplo, "comprovava" a superioridade dos brancos e dos homens.

Dessa forma, uma reflexão mais apurada nos mostra que a ciência não produz a verdade, mas sim, enunciados sobre o mundo, as coisas e os acontecimentos. O que hoje é considerado verdadeiro amanhã pode ser comprovado que não é. Como ensina Thomas Kuhn (2003) quanto maior o conhecimento sobre algo, maior a ruptura dos paradigmas, visões de mundo dentro da esfera cientifica. Igualmente, a visão C\&T, tradicional, afirma que os/as especialistas são pessoas alheias à interferência política e que a pesquisa possui homogeneidade de interesses. Essa prática enfoca a responsabilidade individual, as disciplinas fechadas, a hierarquia autoritária, e seus resultados são avaliados pela comunidade cientifica e são considerados exclusivamente de sua alçada. Para Patricia Muro Gascon (2008), essa visão torna o conhecimento um produto especial em nossa contemporaneidade e abre um dilema entre dois objetivos incompatíveis: garantir o uso social do conhecimento, que é fonte de riqueza e desenvolvimento individual e social, ou incentivar e proteger os produtores privados do conhecimento e suas mercadorias, que embasam a economia do conhecimento.

A Ciência e as tecnologias geram conflitos de interesse e impactam de modos diferentes sobre grupos distintos, implicando um esforço de antecipação das suas consequências, oportunidades e alternativas, tanto para relações sociais e econômicas, quanto para o meio ambiente, observa Ivan Rocha (2002). Nesse contexto, para superar o perigo da submissão da educação à lógica do mercado, dentro de uma perspectiva ampliada, a educação cientifica e tecnológica necessita ser pensada em seus variados contextos - cultural, político, ideológico, de gênero, étnico. Assim está no texto PROEJA:

Apesar dessa dura realidade, existe outro tipo de sociedade que pode ser buscada. Uma sociedade que tenha o ser hu- 
mano e suas relações com o meio-ambiente e a natureza em geral como centro e na qual a tecnologia esteja submetida a uma racionalidade ética no lugar de estar a serviço exclusivo do mercado e do fortalecimento dos indicadores econômicos. Nessa sociedade, a produção coletiva do conhecimento deve estar voltada para a busca de soluções aos problemas das pessoas e das comunidades menos favorecidas na perspectiva da edificação de uma sociedade socialmente justa. (BRASIL, 2007, p 24)

Dessa forma, sem referir os estudos CTS - Ciência, Tecnologia e Sociedade - o documento PROEJA parece ter afinidade com essa concepção, por enfocar a co-responsabilidade social e de cada instituição pública, a partir de um programa nacional, com vistas à formação de cidadãos / cidadãs interessados/as em ciência e tecnologia. No entanto, carece uma explicitação mais efetiva de que Ciência e tecnologia poderia vincular a alteridade efetivamente, para o empoderamento das minorias sociológicas que esta política educacional tem em vista. A conceituação e vinculação das categorias gênero, Ciência e tecnologia demarcaria o lócus do tema, de onde, do que, porque e para quem se fala.

Desde a década de 1980, Fanny Tabak (2001) abordava a necessidade de mudanças substanciais na educação científica e tecnológica no país em relação às mulheres, porém, foi somente a partir de 1980 e 1990 que as mulheres brasileiras aumentaram sua participação no setor. Conforme Margareth Lopes (2002), no Brasil, nas últimas décadas, os avanços das práticas e políticas em C\&T ocasionaram significativas transformações do status jurídico feminino, mas as carreiras científicas e tecnológicas continuam não sendo opções prioritárias para as mulheres, contexto no qual se inserem os cursos do PROEJA.

\section{Considerações finais}

Não obstante o documento PROEJA 2007 apresente concepções emancipatórias em relação ao gênero, este ainda se encontra no texto oficial, não como uma categoria permeando as análises, porém, mais como uma concessão, fruto da exaustiva luta que tem sido travada para que essa alteridade componha as análises das políticas sociais e educacionais. A ca- 
tegoria gênero, no limite, provoca epistemologicamente, assim, para além da sua presença em parágrafos nos documentos, deve ser o fulcro do processo de reconhecimento das pessoas nas situações específicas, permeando as análises e as avaliações, sempre confrontado com os resultados das pesquisas sobre o tema que já temos, no país, em número significativo. O problema também está na categoria gênero aparecer como sinônimo de mulher, como se esta fosse uma entidade, ou um grupo homogêneo e sem relação com as questões de poder demarcadas entre feminino e masculino. Essa redução ainda é uma pratica/concepção limitadora, a ser superada em diferentes instâncias decisórias e educacionais. O reconhecimento que as divisões de poder na sociedade são injustamente assimétricas para imensas camadas da população e notadamente na relação homens e mulheres é ponto pacifico. Imprescindível agora, se torna a aplicação efetiva dessa compreensão, para acabar com o estranhamento preconceituoso que a categoria carreia na Academia e nos meios científicos e tecnológicos.

Para evitar uma concepção e pratica de neutralidade no que tange a educação em Ciência e Tecnologias, importa considerar a responsabilidade cidadã e dos envolvidos, na decisão do que deve ser pesquisado, produzido e utilizado. Nesse sentido, o documento PROEJA carece explicitar mais detalhadamente alguns pontos relacionados à Ciência e tecnologias. Nesse sentido, caberiam alguns questionamentos, na esteira de Londa Schiebinger (2001): sobre qual Ciência e tecnologia estamos falamos? Quem a define? Quem a faz? Porque a fazem? Para quem fazem? Quem participa? Quem financia? Porque financia? Quem detém os saberes? Quais saberes importam? E ao fim e ao cabo, como e de que forma imbricar gênero, ciência e tecnologia? Consideramos que para um desenvolvimento realmente emancipatório e cidadão, devemos aprofundar os estudos que envolvem as comunidades na produção e nos usos da Ciência e das tecnologias. No local de nossa pesquisa, há que se levar em conta a biodiversidade da região, das mais importantes do planeta, e que se encontra na mira do capitalismo de mercado, com sua concepção tradicional de desenvolvimento ligado a ciência e tecnologias caras, excludentes, poluentes. Por fim, em relação à política educacional do PROEJA, importa classificar as tecnologias conforme as características das comunidades, mas especialmente, repetimos, em relação às mulheres, pois estas têm oportunidades diferenciadas de parti- 
cipação, para que não sejam excluídas dos processos científicos e tecnológico, que são oferecidos na forma que o interesse hegemônico considera mais lucrativo e dentro de uma tradição sexista.

\section{Referências}

BRASIL, MEC. Documento Base PROEJA. 2007. Em: http://portal.mec.gov. br/setec/arquivos/pdf2/proeja_medio.pdf. Acesso>20/05/2011.

FRANCO, Maria Ciavatta. O trabalho como Princípio Educativo: Uma investigação Teórico-Metodológica a (1940-1960). Tese (Doutorado em Educação), Pontifícia Universidade Católica, Rio de Janeiro, 1990.

IANNI, Octavio. Teorias da Globalização. Rio de Janeiro: Civilização Brasileira, 2001

KUHN, T. S. A Estrutura das Revoluções Científicas. 7 ed. São Paulo: Perspectiva, 2003.

KUENZER, Acácia (org.). Ensino médio: construindo uma proposta para os que vivem do trabalho. 5. Ed. São Paulo: Cortez, 2007.

LIMA FILHO, Domingos A Desescolarização da Escola: Impactos da Reforma da Educação Profissional (período de 1995 a 2002). Curitiba: Torre de Papel, 2003.

LOPES, M. Margarete. As Grandes Ausentes das Inovações em Ciência e Tecnologia. Cadernos Pagu, no. 19 campinas 2002

MURO GASCÓN, Patrícia. La Economia del conocimiento o la Reinvención del Capitalismo. Veredas 17. UAM: Xochimilco.Mexico, 2008.

NOGUEIRA, V. L. Educação de jovens e adultos e gênero: um diálogo imprescindível à elaboração de políticas educacionais destinadas às mulheres das camadas populares. In: Leôncio José Gomes Soares. (Org.). Aprendendo com a diferença: estudos e pesquisas em educação de jovens e adultos. 2aed.Belo Horizonte: Autêntica, 2006, v. , p. 65-90 
ROCHA, Ivan. Tecnologias Sociais: conceitos \& perspectivas. Revista diálogos, v. 1, p. 8-16, 2002.

SCHIEBINGER, Londa. O Feminismo Mudou a Ciência? São Paulo: EDUSC, 2001.

SEN, Amartya. Desenvolvimento como Liberdade. São Paulo: Companhia das Letras, 2000.

TABAK, Fanny. O Laboratório de Pandora, Rio de Janeiro: Garamond, 2001. 